УДК 378.14.015.62

\title{
ОПЫТ И РЕЗУЛЬТАТ ПЕРЕХОДА НА ДИСТАНЦИОННОЕ ОБУЧЕНИЕ ПО ДИСЦИПЛИНЕ «НЕВРОЛОГИЯ, НЕЙРОХИРУРГИЯ, МЕДИЦИНСКАЯ ГЕНЕТИКА»
}

Николаева Татьяна Яковлевна

д.м.н., доцент

Конникова Эдилия Эдуардовна

к.м.н., доцент

Таппахов Алексей Алексеевич

к.м.Н., доцент

ФГАОУ ВО «Северо-Восточный федеральный университет им. М.К. Аммосова»

\begin{abstract}
Аннотация: В статье авторы делятся своим опытом перехода на дистанционное обучение по дисциплине «Неврология, нейрохирургия, медицинская генетика». Проанализирован опыт применения системы электронного и дистанционного обучения (СЭДО), подчеркнуты сложности, недостатки и положительные стороны дистанционного обучения. Проведено сравнительное изучение результатов промежуточной аттестации в режиме оффлайн и онлайн. Несмотря на неплохие результаты экзамена, оценивать практические навыки у студентов, прошедших дистанционного обучения, сложно. Для преподавания клинических дисциплин вариант оффлайн с применением информационных технологий является самым приемлемым.
\end{abstract}

Ключевые слова: дистанционное обучение, информационные технологии, неврология, нейрохирургия, медицинская генетика, COVID-19. 


\title{
EXPERIENCE AND RESULT OF TRANSITION TO DISTANCE LEARNING ON THE DISCIPLINE "NEUROLOGY, NEUROSURGERY, MEDICAL GENETICS"
}

\section{Nikolaeva Tatiana Yakovlevna Konnikova Edilia Eduardovna Tappakhov Alexey Alekseevich}

\begin{abstract}
In the article, the authors share their experience of transition to distance learning in the discipline "Neurology, neurosurgery, medical genetics." The experience of using SEDO is analyzed, the difficulties, disadvantages and advantages of distance learning are highlighted. A comparative study of the results of intermediate certification in offline and online mode was carried out. Despite the good results of the exam, it is difficult to assess the practical skills of students who have completed distance learning. For teaching clinical disciplines, the offline option with the use of information technology is the most acceptable.
\end{abstract}

Key words: distance learning, information technology, neurology, neurosurgery, medical genetics, COVID-19.

Всемирная организация здравоохранения 11 марта 2020 года объявила вспышку новой коронавирусной инфекции (COVID-19) пандемией. Для предупреждения распространения коронавируса в России Министерство науки и высшего образования поручило подведомственным вузам усилить меры по обеспечению безопасных условий обучения и воспитания, а также применять электронное обучение и дистанционные образовательные технологии. Начиная с 17 марта 2020 г., Северо-Восточный федеральный университет им. М.К. Аммосова (СВФУ) перевел реализацию образовательных программ высшего и среднего профессионального образования на режим контактной работы обучающихся и педагогических работников в электронной информационно-образовательной среде с применением электронного обучения и дистанционных образовательных технологий [1,2]. В соответствии с требованиями ФОС $3+$, обучение по программе специалитета по направлениям 31.05.01 «Лечебное дело» и 31.05 .02 «Педиатрия» допускается только в образовательной организации высшего образования и в очной форме обучения. При реализации программы специалитета по данным направлениям, учебная организация вправе 
применять электронное обучение и дистанционные образовательные технологии. Реализация программы специалитета также возможна с использованием сетевой формы. Для этого организация должна располагать материально-технической базой, соответствующей действующим правилам и нормам и обеспечивающей проведение всех видов дисциплинарной и междисциплинарной подготовки, практической и научно-исследовательской работ обучающихся, предусмотренных учебным планом. Электронная информационно-образовательная среда организации должна обеспечивать: доступ к учебным планам, рабочим программам дисциплин (модулей), практик, к изданиям электронных библиотечных систем и электронным образовательным ресурсам, указанным в рабочих программах; фиксацию хода образовательного процесса, результатов промежуточной аттестации и результатов освоения основной образовательной программы; проведение всех видов занятий, процедур оценки результатов обучения, реализация которых предусмотрена с применением электронного обучения, дистанционных образовательных технологий. В случае реализации программы специалитета в сетевой форме допускается замена специально оборудованных помещений их виртуальными аналогами, позволяющими обучающимся осваивать умения и навыки, предусмотренные профессиональной деятельностью $[3,4]$.

В результате освоения программы специалитета у выпускника должны быть сформированы общекультурные, общепрофессиональные и профессиональные компетенции по соответствующим направлениям подготовки. Дисциплина «Неврология, нейрохирургия, медицинская генетика» относится к базовой части основной образовательной программы по специальностям «Лечебное дело» и «Педиатрия». Целью освоения дисциплины является овладение студентами знаниями об этиологии, патогенезе и клинических проявлениях основных заболеваний нервной системы, а также формирование у обучающихся навыков обследования, диагностики и дифференциальной диагностики, лечения и профилактики неврологических, нейрохирургических и наследственных заболеваний нервной системы. Курс состоит из лекций и практических занятий, самостоятельной работы студентов с изучением топической анатомии и физиологии нервной системы, клинической неврологии, нейрохирургии, медицинской генетики. Для успешного усвоения курса на лекциях особое внимание уделяется современным методам обследования, лечения и профилактики заболеваний центральной и периферической нервной системы. На практических занятиях 
закрепляется как базовый, так и дополнительный материал по избранным темам клинической неврологии, а также закрепляются умения выявления симптомов поражения нервной системы, интерпретации данных инструментальных обследований. Текущий контроль осуществляется в виде опроса, проверки рабочего альбома, терминологического словаря, конспектов самостоятельной работы студента (СРC). Промежуточный контроль осуществляется в виде тестов, сдачи зачета. По окончании модуля «Частная неврология» студенты защищают историю болезни. Итоговый контроль заключается в сдаче экзамена.

При переходе на дистанционный формат студенты потеряли возможность пребывания в клинике, осмотра тематических пациентов. Историю болезни писали по виртуальному пациенту с помощью преподавателя. Известно, что в процессе дистанционного обучения практически каждый студент $(73,4 \%)$ имеет трудности в выполнении практических заданий без объяснений преподавателя [5]. Вместе с тем, наличие в СВФУ системы электронного и дистанционного обучения (Moodle) обеспечило быстрый переход на онлайн обучение.

Цель исследования: оценить собственный опыт полного перехода на режим контактной работы обучающихся и преподавателей в системе электронного и дистанционного обучения и сравнить результаты промежуточной аттестации в режиме оффлайн и онлайн.

Материалы исследования: учебно-методический комплекс дисциплины, экзаменационный ведомости студентов лечебного и педиатрического факультетов за 2019 г. и 2020 г.

Результаты и обсуждение. Для реализации учебного процесса по дисциплине «Неврология, нейрохирургия, медицинская генетика» студентам 4 курса лечебного и педиатрического отделений в условиях пандемии новой коронавирусной инфекции нами полностью реализована технология модульного обучения (более подробное изложение далее по тексту) с использованием видеоконференции.

Для проведения лекционных занятий наша кафедра использует программу для организации видеоконференций ZOOM. Ссылка для подключения к занятию формируется за день и рассылается на общую рабочую группу студентов, а также лично старосте курса. При планировании занятия преподаватель устанавливает дополнительную защиту, а именно: включает функцию «зал ожидания», по умолчанию у студентов включает 
видео (в т.ч. для дополнительного контроля присутствия) и для подавления лишнего шума выключает звук при подключении.

Лектор, как правило, подключается за 5-10 минут до начала занятия, дает доступ студентам, ожидающим подключения к видеоконференции. В лекциях презентация учебного материала демонстрируется с использованием собственного экрана. Одним из основных ограничений организации дистанционных лекционных занятий является отсутствие автоматической отметки присутствия студентов в бесплатной версии программы ZOOM, однако в корпоративной версии после проведения занятия преподаватель может скачать протокол видеоконференции. В этом случае важно, чтобы студенты подключались с использованием подлинных имен (не никнеймов), а также указали номер учебной группы. Студенты во время лекции могут задавать вопросы преподавателю устно, включив микрофон, а также написать в чат. После занятия презентация лекции в формате PDF размещается в СЭДО СВФУ Moodle.

Семинарские занятия проводятся с использованием СЭДО СВФУ и программы для организации видеоконференций ZOOM. Курс «Неврологии, нейрохирургии, медгенетики» в СЭДО СВФУ состоит из нескольких разделов (модулей). В нормативном блоке размещается рабочая программа дисциплины, тематический и календарный план лекционных и практических занятий, рейтинговый регламент по дисциплине согласно балльнорейтинговой системе Университета и список литературы для подготовки к занятиям. Методический блок включает схему истории болезни неврологического больного, различные атласы, учебные пособия и учебники. Практический блок содержит видеофайлы по практическим навыкам, а именно по оценке неврологического статуса. В условиях удаленной работы и отсутствия реальной курации пациентов видеофайлы являются вынужденной заменой практической части дисциплины.

Далее следуют отдельные разделы (модули) согласно тематическому плану дисциплины (рис 1). 


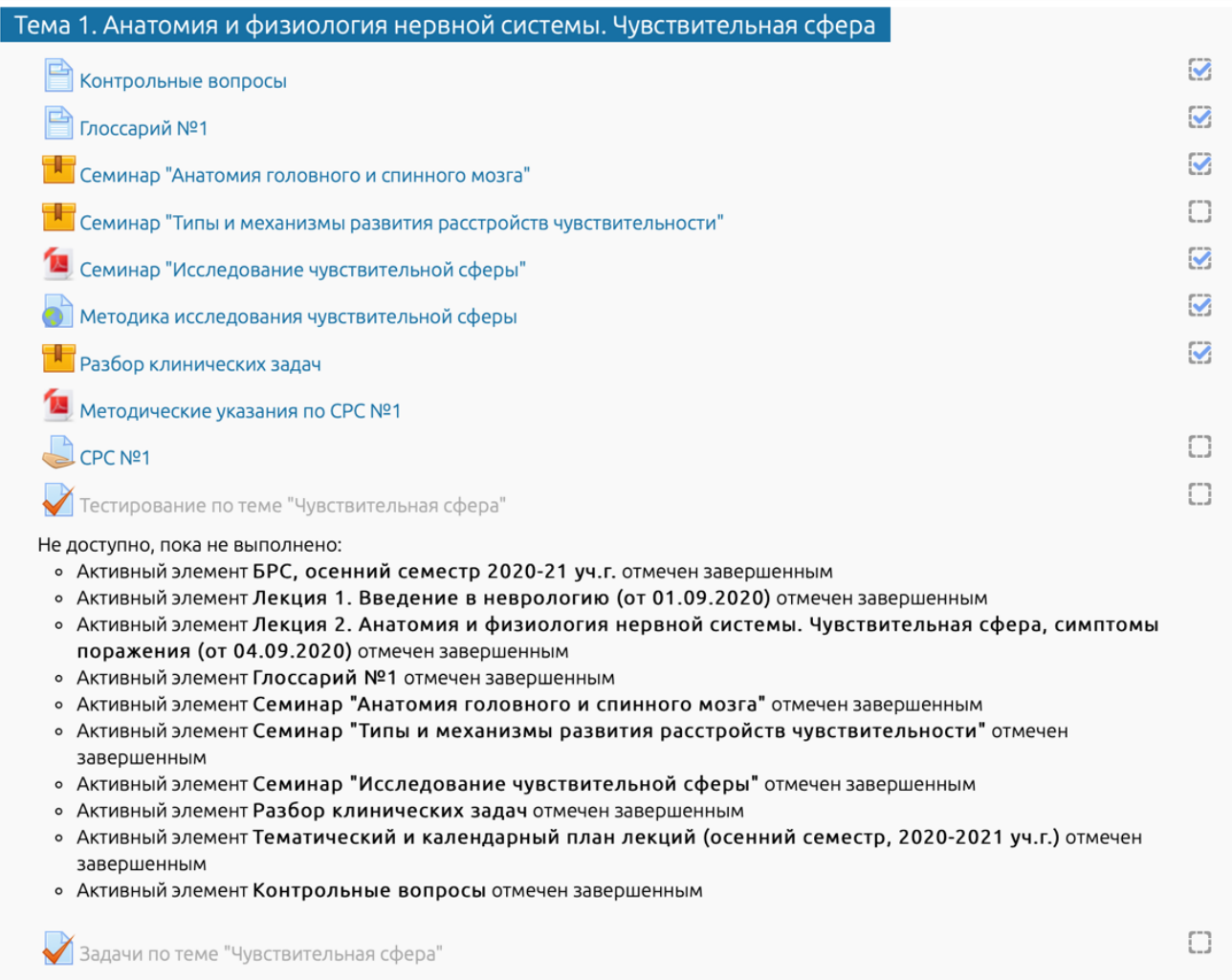

\section{Рис. 1. Содержание темы 1. При прохождении материала предусмотрена автоматическая фиксация выполнения (галочка в квадратике справа)}

По каждой теме размещены контрольные вопросы, по которым студенты готовятся к предстоящему занятию; глоссарий для заполнения терминологического словаря.

Семинарские занятия проводятся с использованием программы для видеоконференций ZOOM или Google Meet. Преподаватель заблаговременно планирует конференцию, ссылку отправляет старосте группы. Занятия идут с обязательным включением видео- и аудиопотоков. Согласно плану занятий проводятся опросы, дискуссии, обсуждения, демонстрации виртуальных пациентов, разборы историй болезни.

Учитывая вероятность отсутствия у части студентов Интернета с достаточной пропускной способностью для подключения к видеоконференции по каждой теме размещены материалы семинарских занятий. Для максимального приближения к реальным семинарским занятиям нами подготовлены материалы в формате SCORM с видео- и звуковым сопровождением (рис. 2). Разборы некоторых клинических случаев и задач также подготовлены в формате SCORM. 


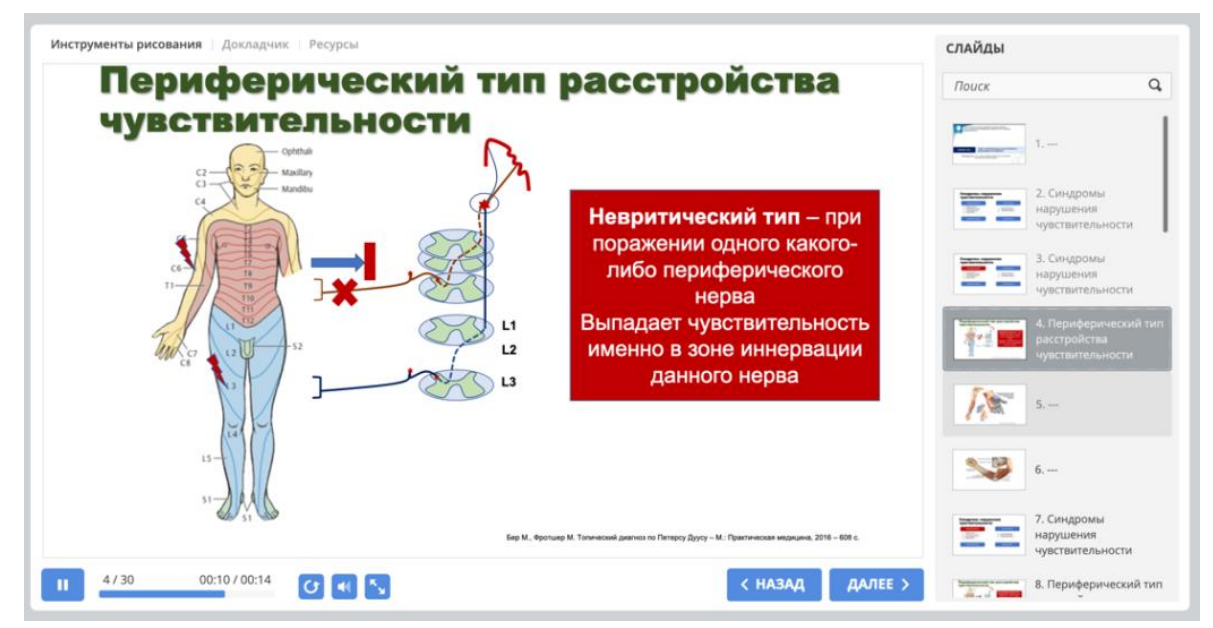

\section{Рис. 2. Пример проведения занятия в формате SCORM}

Кроме того, в СЭДО размещены методические указания для выполнения самостоятельной работы студента. Данный вид работы студенты выполняют в альбомах, затем сканируют или фотографируют, объединяют все рисунки в один PDF файл и через специальное задание направляют преподавателю на проверку.

В СЭДО реализована также автоматическое тестирование по теме занятия. Система случайным образом отбирает 10 вопросов из общего банка вопросов. Ограничение по времени составляет 10 минут (из расчета 1 вопрос 1 минута). Студент, набравший 70\% и более баллов по тестированию, получает доступ для решения ситуационных задач. В зависимости от тематики занятия система автоматически отбирает из общего банка 1-2 задачи, на которые студент должен дать развернутый ответ на поставленные вопросы. Ограничение по времени составляет 5 минут до одной задачи, 10 минут - для двух. Задачи проверяются преподавателем вручную. На наш взгляд, одним из ограничений такого рода контроля знаний является пользование студентами учебных пособий, Интернета и других источников. В этой связи ограничение по времени мы считает крайне необходимым условием. В будущем эта проблема может разрешиться путем массового внедрения системы прокторинга.

Как отмечалось выше, отсутствие курации пациентов является одним из основных ограничений дистанционного формата обучения. В то же время грамотное написание истории болезни, изложение динамики развития заболевания, определение очага поражения (топического диагноза) на основании неврологического статуса, проведение дифференциальной диагностики, назначение правильного лечения и определение прогноза 26 
необходимо для формирования как общих, так и профессиональных компетенций будущего врача. Поэтому преподавателем раздаются клинические ситуации, по которым студент должен написать подробную историю болезни. Истории болезни защищаются, студенты получают оценки согласно регламенту дисциплины по балльно-рейтинговой системе (БРС).

Экзамен по дисциплине принимается с использованием системы видеоконференции Google Meet и СЭДО СВФУ. Видеокамера студента размещается так, чтобы преподаватель мог видеть рабочую зону. Мы отказались от способа приема экзамена путем тестирования (которая считается более удобной и подходящей формой контроля знаний для дистанционного обучения) и предпочтение отдали традиционному собеседованию. Экзаменационные вопросы и задачи загружены в отдельный раздел банка вопросов. Для проведения контроля нами создано задание, которое случайным образом отбирает три вопроса из каждого раздела дисциплины (общая неврология, частная неврология, медицинская генетика / нейрохирургия) и одну задачу. После подключения всех экзаменуемых и проверки обратной связи каждый студент входит в СЭДО СВФУ и формирует свой экзаменационный билет. На подготовку отводится 30 минут. Студенты отвечают устно, письменный ответ по форме СЭДО не заполняется. На рисунке 3 показан пример экзаменационного билета в СЭДО СВФУ.

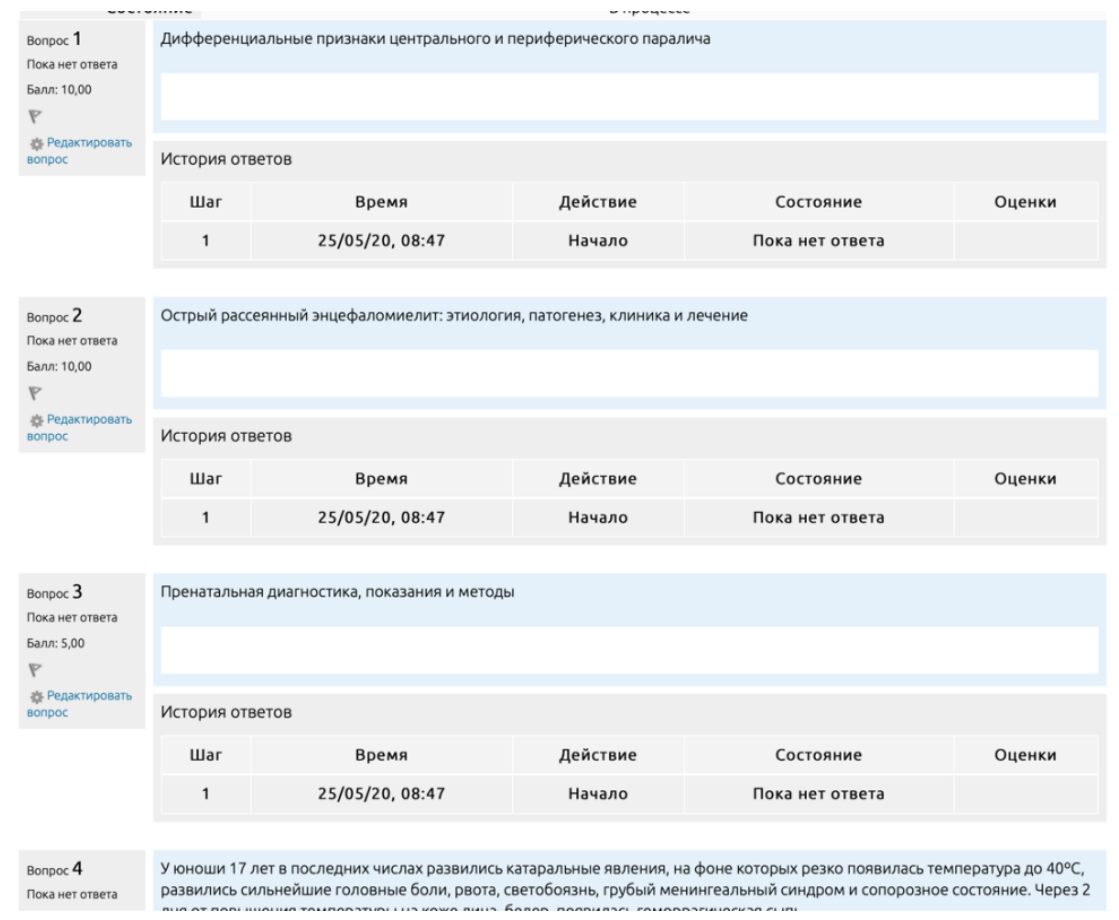

Рис. 3. Пример экзаменационного билета. Система случайным образом отбирает три вопроса и одну ситуационную задачу 
Результаты экзаменационной сессии 2020 года, в сравнении с прошлым 2019 годом, показали улучшение показателей по успеваемости и качеству знаний у студентов по направлению «Лечебное дело». В 2019 г. к экзамену были допущены 86 студентов, в 2020 г. экзамен сдавали 86 студентов. Успеваемость повысилась с 93\% до 95\%, а качество - с 87,4\% до 94 \% (рис. 4), средний балл повысился с 4,17 до 4,3 баллов (рис. 5). Экзамен автоматом без прохождения промежуточной аттестации (согласно положению о балльнорейтинговой системе СВФУ) получили 45 студентов, что составило $52 \%$ от числа всех студентов. По сравнению с прошлым годом доля студентов, получивших экзамен автоматом, увеличилась на 32,2\% (с 19,8\%), что связано с дистанционным обучением и дополнительными бонусными баллами студентам за участие в борьбе с COVID-19 (волонтерство, работа в больнице, в «красной зоне», эпидемиологических бригадах).

В 2019 г. по направлению «Педиатрия» к экзамену были допущены 38 студентов, в 2020 г. экзамен сдавали 49 человек. Студенты педиатрического отделения незначительно снизили показатели успеваемости и качества с $88,9 \%$ до $86,0 \%$ (на $2,9 \%$ ) и с $87 \%$ до $85 \%$ (на $2,0 \%$ ) соответственно (рис. 4 ). Несмотря на это повысился средний балл с 3,9 до 4,1 (рис. 5).

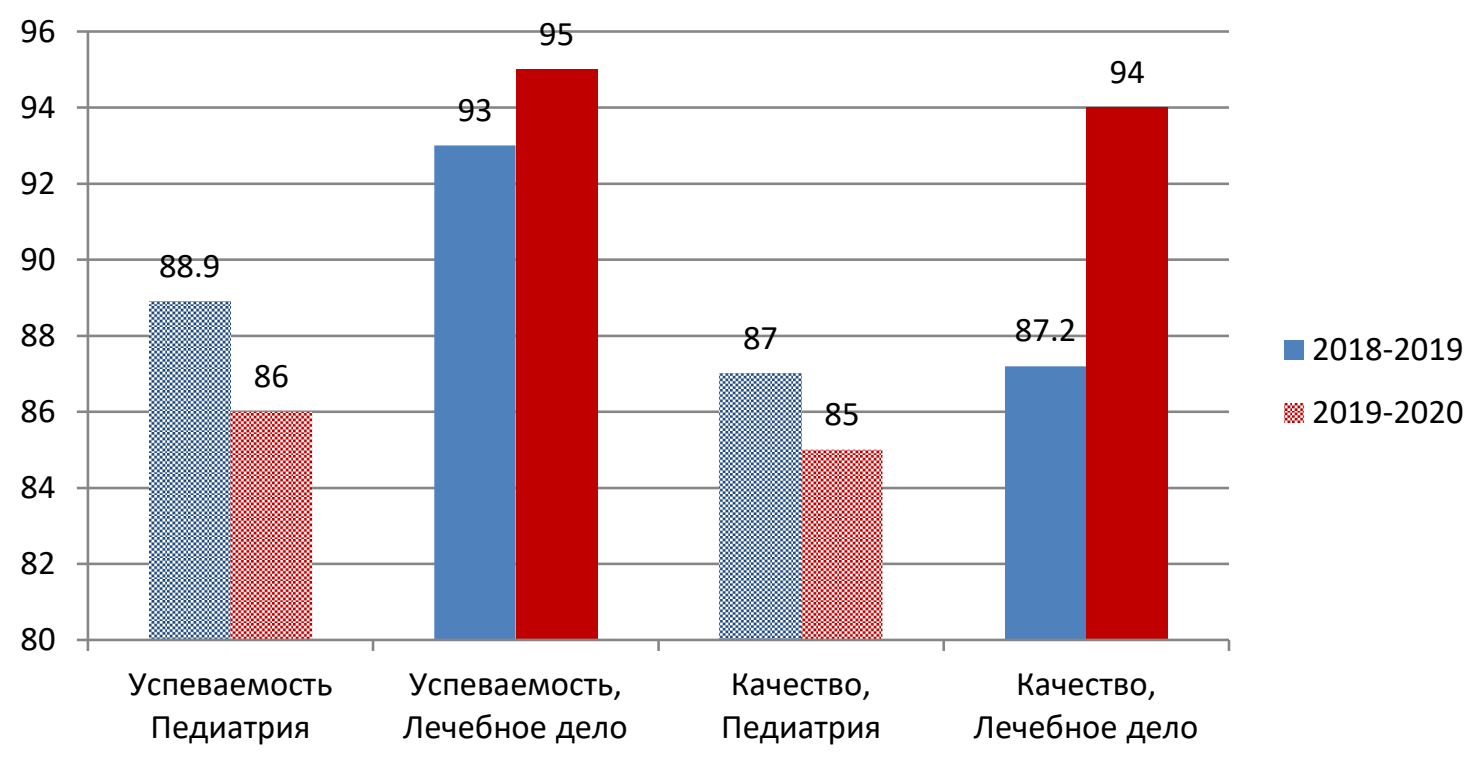

\section{Рис. 4. Сравнительная успеваемость и качество по дисциплине}

«Неврология, нейрохирургия, медицинская генетика» у студентов по направлению «Педиатрия» и «Лечебное дело» в 2018-2019 г. (оффлайн) и в 2019-2020 г. (онлайн) (в \%) 


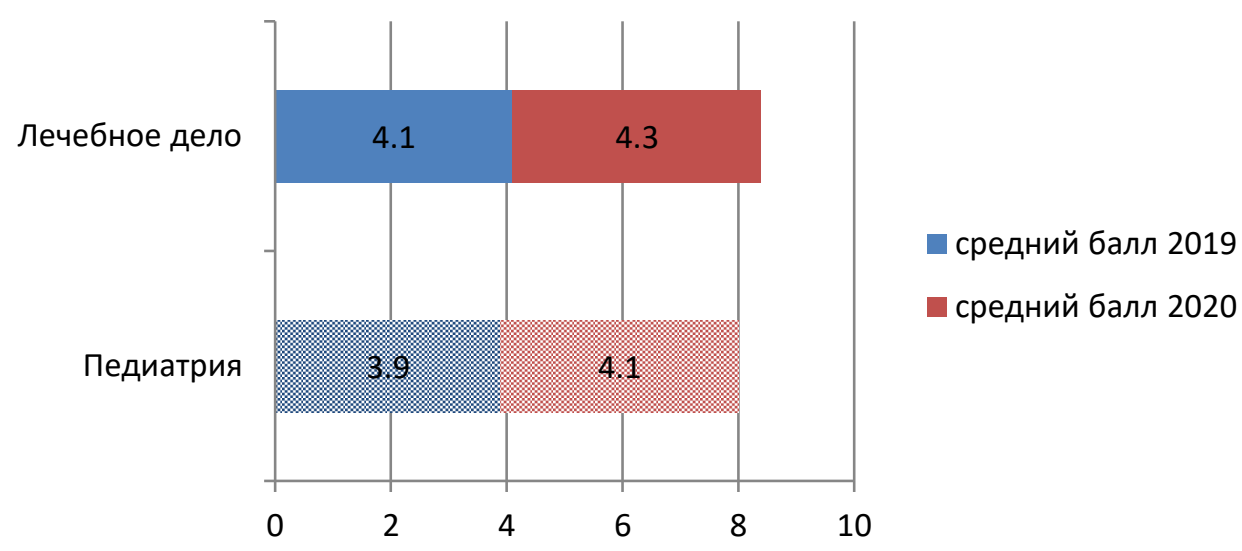

Рис. 5. Средний балл по дисциплине «Неврология, нейрохирургия, медицинская генетика» у студентов по направлению «Педиатрия» и «Лечебное дело» в 2018-2019 г. (оффлайн) и в 2019-2020 г. (онлайн)

Заключение. Таким образом, введение дистанционного обучения с 17 марта 2020 года существенно не повлияло на результаты экзаменационной сессии, несмотря на изменение формата приема экзаменов. Экзамен принимали коллегиально в системе Google Meet с использованием СЭДО CВФУ Moodle и ограничением времени подготовки. Во многом этому способствовала мобилизация студентов, быстрая адаптация к электронному обучению в системе MOODLE c использованием систем для видеоконференции ZOOM и Google Meet для дистанционного обучения. Кроме того, использовали электронную почту и мессенджер WhatsApp. Отрицательными моментами в дистанционном обучении клинических дисциплин являются недостаток практики, что скажется на практических умениях и навыках студентов, а также отсутствие непосредственного, индивидуального контакта с преподавателями и пациентами.

\section{Список литературы}

1. Приказ Министерства науки и высшего образования РФ от 14 марта 2020 г. № 397 «Об организации образовательной деятельности в организациях, реализующих образовательные программы высшего образования и соответствующие дополнительные профессиональные программы, в условиях предупреждения распространения новой коронавирусной инфекции на территории Российской Федерации». 
2. Приказ от 16.03.2020г № 239-ОД «Об организации деятельности Северо-Восточного федерального университета в условиях предупреждения распространения новой коронавирусной инфекции».

3. Федеральный государственный образовательный стандарт высшего образования. Уровень образования специалитет. Специальность 31.05.01. Лечебное дело. Утвержден приказом Министерства образования и науки Российской Федерации от 9 февраля 2016 г. N 95.

4. Федеральный государственный образовательный стандарт высшего образования. Уровень образования специалитет. Специальность 31.05.02. Педиатрия. Утвержден приказом Министерства образования и науки Российской Федерации от 17 августа 2015 г. N 853.

5. Кулик Е. Г. Использование IT-технологий в преподавании дисциплины «факультетская терапия» / Е. Г. Кулик, С.В. Нарышкина, В.И. Павленко // Сборник статей III Всероссийской научно-методической конференции, 11 февраля 2021 г. - Петрозаводск. - С. 205-212.

() Т.Я. Николаева, Э.Э. Конникова, А.А. Таппахов, 2021 